\title{
HIV prevention trials in danger of grinding to a standstill
}

Researchers unable to get meaningful data on effectiveness of new treatments

\section{Erika Check}

In the ongoing battle against AIDS, a great deal of hope is resting on ways to prevent HIV infection in the first place. As efforts to create an HIV vaccine are floundering from a lack of effective candidates, early trials on other prevention methods are beginning to grab the headlines. But the logistical and ethical hurdles that have stalled recent trials are making scientists wonder whether these strategies will ever be able to get off the starting blocks.

In August, Cellegy, the company behind one of the prevention strategies, announced that it was halting a trial in 2,152 women in Nigeria. Cellegy and the non-profit organization Family Health International were testing a vaginal microbicide called Savvy with funding from the US Agency for International Development, to see whether it could cut the rate of new HIV infections in women. But the trial's Data Monitoring Committee decided that the trial should be halted because the rate of new infections in the trial was so low that it would not be possible to detect whether Savvy was having any effect.

Richard Williams, Cellegy's chairman, said the company was disappointed by the premature end to the trial - all the more so because another Savvy trial in Ghana was stopped last November for the same reason. Scientists believe both trials found fewer than expected new HIV infections because of the success of intensive HIV prevention messages provided during the trial. Ethics standards demand that trial participants must also receive existing prevention measures, involving counselling participants about safer sex practices and handing out condoms. As a result, only $2 \%$ of women became infected with HIV each year in the Nigerian trial. The trial's leaders had predicted that $3.7 \%$ of the women would become newly infected.

"The reason we're trying to develop microbicides is because it's so hard to get people to use condoms," says Rowena Johnston, Director of Research for the American

Foundation for AIDS Research, which was not involved in the cancelled trials. "It's a strange irony that using the product you want to find a replacement for is making your trial obsolete."
Similar issues are dogging prevention trials with anti-HIV drugs. At the XVI International AIDS Meeting in Toronto, Leigh Peterson of Family Health International announced that the group had completed the world's first clinical trial of a prevention strategy known as pre-exposure prophylaxis, or PrEP. The strategy aims to provide marketed drugs to uninfected women before sex to see whether it can prevent HIV infection.

\section{It's a strange irony that using} the product you want to find a replacement for is making your trial obsolete

PrEP has been highly controversial, and activists' concerns over patient rights have led to the shut-down of two PrEP trials. So the completed Family Health International trial with the antiretroviral Viread (tenofovir; Gilead) was regarded as a watershed. But it failed to find significant results because HIV infection rates were too low in its 936 participants. "We did not obtain enough seroconversions to detect efficacy," Peterson said at the meeting. "What we have to do is perhaps increase our sample size."
A report from 50 AIDS experts issued during the Toronto meeting agreed that prevention trials need to be dramatically increased in size. The report, called 'New Approaches to HIV Prevention', and funded by the Henry J. Kaiser Family Foundation and the Bill \& Melinda Gates Foundation, concluded that testing these approaches will require 80,000 research participants - far more than are currently enrolled in trials.

In the face of such staggering numbers, and the dramatic rise in costs that this will incur, researchers must make hard choices about which prevention candidates they actually move to the clinical trial stage. And they should work to prepare communities to use the strategies; right now, nobody is ready to implement a new method, should it be proven effective, the report warns. For instance, convincing men to accept circumcision will require a major public relations blitz.

Scientists in the microbicide field are already discussing how to attack some of these challenges. The field issued its own Microbicide Development Strategy — funded by the Gates Foundation and the Alliance for Microbicide Development - at the AIDS meeting. The document spelled out several issues, from lack of funding to a dearth of scientific markers that could be used to guide microbicide development. Renee Ridzon, of the Gates Foundation, said that tackling these issues must be a priority for the HIV prevention field.

"These trials are complex and costly, but there's a moral imperative to do them," says Ridzon, "so we need to think hard and get smart about how we're going to do this."

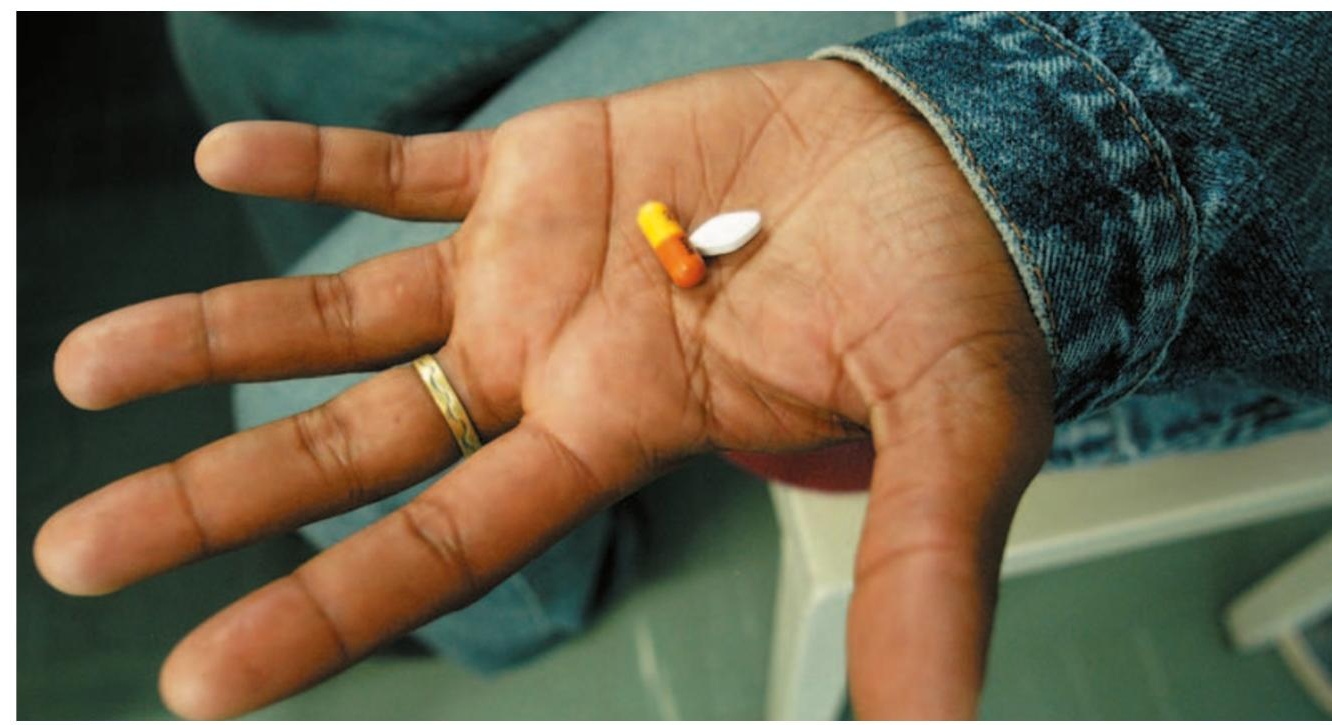

Trials on HIV prevention treatments are stalling because of the success of existing prevention measures. UNAIDS 